\title{
Dose reduction of bone morphogenetic protein-2 for bone regeneration using a delivery system based on lyophilization with trehalose
}

This article was published in the following Dove Press journal: International Journal of Nanomedicine

\author{
Xiaochen Zhang ${ }^{1, *}$ \\ Quan $\mathrm{Yu}^{2, *}$ \\ Yan-an Wang' \\ Jun Zhao ${ }^{2}$
}

'Department of Oral and Maxillofacial-Head and Neck Oncology, ${ }^{2}$ Department of Orthodontics, College of Stomatology, Ninth People's Hospital, School of Medicine, Shanghai Jiao Tong University, Shanghai, China

*These authors contributed equally to this work

Correspondence: Jun Zhao

Department of Orthodontics, College of Stomatology, Ninth People's Hospital, School of Medicine, Shanghai Jiao Tong University, 639 Zhizaoju Road, Shanghai 2000 II, China

Tel +862163135412

$\mathrm{Fax}+862163136856$

Email yuzj_260@hotmail.com

\section{Yan-an Wang}

Department of Oral and MaxillofacialHead and Neck Oncology, College of Stomatology, Ninth People's Hospital, School of Medicine, Shanghai Jiao Tong University, 639 Zhizaoju Road, Shanghai 2000 II, China

Tel +862163135412

Fax +862163136856

Email wangyan_an@I63.com
Introduction: To induce sufficient new bone formation, high doses of bone morphogenetic protein-2 (BMP-2) are applied in regenerative medicine that often induce serious side effects. Therefore, improved treatment strategies are required. Here, we investigate whether the delivery of BMP-2 lyophilized in the presence of trehalose reduced the dose of BMP-2 required for bone regeneration.

Materials and methods: A new growth factor delivery system was fabricated using BMP-2loaded $\mathrm{TiO}_{2}$ nanotubes by lyophilization with trehalose ( $\mathrm{TiO}_{2}$-Lyo-Tre-BMP-2). We measured BMP-2 release characteristics, bioactivity, and stability, and determined the effects on the osteogenic differentiation of bone marrow stromal cells in vitro. Additionally, we evaluated the ability of this formulation to regenerate new bone around implants in rat femur defects by microcomputed tomography (micro-CT), sequential fluorescent labelling, and histological analysis. Results: Compared with absorbed BMP-2-loaded $\mathrm{TiO}_{2}$ nanotubes $\left(\mathrm{TiO}_{2}-\mathrm{BMP}-2\right)$, $\mathrm{TiO}_{2}$-LyoTre-BMP-2 exhibited sustained release, consistent bioactivity, and higher stability of BMP-2, and resulted in greater osteogenic differentiation of BMSCs. Eight weeks post-operation, $\mathrm{TiO}_{2}$-Lyo-Tre-BMP-2 nanotubes, with various dosages of BMP-2, regenerated larger amounts of new bone than $\mathrm{TiO}_{2}$-BMP-2 nanotubes.

Conclusion: Our findings indicate that delivery of BMP-2 lyophilized with trehalose may be a promising method to reduce the dose of BMP-2 and avoid the associated side effects.

Keywords: bone morphogenetic protein-2, dose reduction, delivery system, trehalose, lyophilization, $\mathrm{TiO}_{2}$ nanotubes, BMP-2, regenerative medicine, surface modification

\section{Introduction}

Bone morphogenetic proteins (BMPs) are a family of bone growth factors that strongly induce new bone formation. ${ }^{1}$ Among BMPs, BMP-2 is considered to be the most potent and has been widely used to regenerate bone. ${ }^{2-5}$ As BMP-2 may be easily lost from implanted sites through diffusion or because of its short in vivo half-life, high doses are often applied for clinical treatment. ${ }^{6,7}$ However, high dosages of BMP-2 increase the cost of treatment and also cause unexpected serious complications, including ectopic new bone formation, osteolysis, excessive immune responses, postoperative neurological impairment, and compromised airways. ${ }^{8-10}$ Therefore, novel methods for reducing the dose of BMP-2 are needed to prevent the occurrence or reduce the severity of these adverse effects.

The osteogenic bioactivity, capacity, and optimum dose of BMP-2 for achieving effective bone regeneration depend on the system for BMP-2 delivery. ${ }^{11,12}$ Therefore, it is necessary to develop an appropriate delivery system for BMP-2 in order to reduce 
the dose required for bone regeneration. Owing to their good biological performance, $\mathrm{TiO}_{2}$ nanotube layers have been extensively studied and used as carrier materials in regenerative medicine. ${ }^{13-15}$ Coadministration of growth factors, such as BMP-2, with $\mathrm{TiO}_{2}$ nanotube layers may significantly increase the osteoinductive capacity. ${ }^{16}$ However, the local delivery of growth factors also has several shortcomings, including uncontrolled flow and potential inactivation by heat, extreme $\mathrm{pH}$, or proteases, thereby shortening the duration of efficacy. ${ }^{17,18}$ Accordingly, the loading of biological molecules onto scaffolds by coating them via lyophilization has recently gained interest. Lyophilization, also referred to as freeze-drying, is an efficient approach that has been commonly applied to improve the chemical and physical stability of biomolecules. ${ }^{19}$ However, this process generates various stresses that may lead to the inactivation of biomolecules during the freezing and drying steps. ${ }^{20,21}$ Hence, protectants are often employed to keep biomolecules from freezing and desiccation stresses. ${ }^{22}$ Trehalose, a naturally nonreducing disaccharide present in diverse organisms, is the most potent and widely studied stabilizer, exhibiting several advantages over other materials, including reduced rates of fermentation, non-toxicity, and a slower $\mathrm{pH}$ response. ${ }^{23,24}$ Lyophilized calcium-deficient hydroxyapatite scaffolds with trehalose have been shown to enable long-term release of BMP-2 while retaining protein activity and stability. ${ }^{25}$ Recent studies have used lyophilized BMP-2 with the addition of trehalose (Lyo/Tre) loaded on scaffolds for enhanced osteogenesis. ${ }^{25,26}$ However, despite these advantages of preserving protein activity and stability, the potential applications of Lyo/Tre for BMP-2 dose reduction have not been studied to date.

In this work, we aim to determine whether the delivery of BMP-2 lyophilized in the presence of trehalose (Lyo/Tre) reduced the BMP-2 dose required for effective bone regeneration. A new growth factor delivery system was fabricated using BMP-2-loaded $\mathrm{TiO}_{2}$ nanotubes by lyophilization following the addition of trehalose ( $\mathrm{TiO}_{2}$-Lyo-Tre-BMP-2). We measured BMP-2 release characteristics, bioactivity, and stability, and determined the effects of this BMP-2 formulation on osteogenic differentiation of bone marrow stromal cells (BMSCs) in vitro. Furthermore, we examined the ability of $\mathrm{TiO}_{2}$-Lyo-Tre-BMP-2 to regenerate new bone around implants in rat femur defects. The bone formation around implants induced by $\mathrm{TiO}_{2}$-Lyo-Tre-BMP-2 was compared with that induced by BMP-2-loaded $\mathrm{TiO}_{2}$ nanotubes $\left(\mathrm{TiO}_{2}\right.$-BMP-2) to determine whether the new delivery system for BMP-2 allows reduction of the dose required for new bone formation.

\section{Materials and methods Substrate preparation}

The $\mathrm{TiO}_{2}$ nanotube layers were fabricated using Ti thin foils (thick, $0.25 \mathrm{~mm}$ ) or rods (diameter, $2 \mathrm{~mm}$; length, $8 \mathrm{~mm}$ ) with a purity of $99.5 \%$ (Alfa Aesar, Ward Hill, MA, USA) by anodization. First, the Ti foils or rods were immersed in a mixture ( $2 \mathrm{~mL}$ of $48 \%$ hydrofluoric acid (HF), $3 \mathrm{~mL}$ of $70 \%$ $\mathrm{HNO}_{3}$, and $100 \mathrm{~mL}$ of deionized water) for $5 \mathrm{~min}$ to remove the naturally formed outer oxide layer, followed by rinsing in deionized water and drying under a nitrogen stream. Then, the nanotubes were fabricated in an electrolyte solution containing $0.5 \% \mathrm{HF}(\mathrm{w} / \mathrm{v})$ and $1 \mathrm{M} \mathrm{H}_{3} \mathrm{PO}_{4}$ with a potentiostat (voltage, $20 \mathrm{~V}$ ) for $3 \mathrm{~h} .{ }^{27}$ Finally, the samples were sintered at $500^{\circ} \mathrm{C}$ for $2 \mathrm{~h}$ to crystallize the as-deposited amorphousstructured $\mathrm{TiO}_{2}$ nanotubes. All nanotubes were sterilized in a steam autoclave at $120^{\circ} \mathrm{C}$ for $30 \mathrm{~min}$ before use.

\section{BMP-2 radio-iodination and nanotube loading}

To investigate the release kinetics of BMP-2 in vitro, the loaded BMP-2 (Rebone, Shanghai, China) was radiolabeled with ${ }^{125} \mathrm{I}$ and the final concentration of ${ }^{125} \mathrm{I}$-BMP-2 was adjusted to $0.2 \mathrm{mg} / \mathrm{mL}$ in PBS, as previously described. ${ }^{28}$ For the lyophilization of the BMP-2 group, ${ }^{125}$ I-BMP-2 solution mixed with $1 \mathrm{M}$ trehalose ${ }^{18}$ at a fixed volume of $30 \mu \mathrm{L} /$ sample was dripped onto $\mathrm{TiO}_{2}$ nanotubes prepared on foil $\left(\mathrm{TiO}_{2}\right.$-Lyo-TreBMP-2). Using this method, each foil was loaded with $6 \mu \mathrm{g}$ of ${ }^{125} \mathrm{I}$-BMP-2. Then, ${ }^{125} \mathrm{I}-\mathrm{BMP}-2$ solution $(0,1.5,2.5$, or $5 \mu \mathrm{L})$ was mixed with $1 \mathrm{M}$ trehalose at a fixed volume of $30 \mu \mathrm{L}$ and dripped onto nanotubes for preparation of implants. In this manner, each implant was loaded with $0,0.3,0.5$, or $1.0 \mu \mathrm{g}$ of ${ }^{125} \mathrm{I}$-BMP-2. All samples were pre-frozen at $-80^{\circ} \mathrm{C}$ for $3 \mathrm{~h}$ prior to being lyophilized for $24 \mathrm{~h}$ in a FreeZone freeze-drier (Labconco, Kansas City, MO, USA). For the absorption group, the same ${ }^{125} \mathrm{I}$-BMP-2 solution without trehalose was physically dripped onto the $\mathrm{TiO}_{2}$ nanotubes of the foil or implant $\left(\mathrm{TiO}_{2}-\right.$ BMP-2), using the same method, for $30 \mathrm{~min}$ before use.

\section{Scanning electron microscopy observations and Fourier transform infrared spectroscopy analysis}

A Quanta 200 field-emission gun scanning electron microscope (SEM XL-30; Philips, Amsterdam, the Netherlands) was employed to observe the surface morphology of the samples. All samples were sputter-coated with platinum prior to imaging for $1 \mathrm{~min}$. Surface chemical characterization of the samples was performed using Fourier transform infrared 
spectroscopy (FTIR, Nicolet Avatar 660; Nicolet, Madison, WI, USA), in the wavelength range of $600-4,000 \mathrm{~cm}^{-1}$.

\section{Ethics statement}

All experiments were approved by the Animal Care and Experimental Ethics Committee of the Ninth People's Hospital affiliated with the Shanghai Jiao Tong University School of Medicine and performed in accordance with standard animal research guidelines published by National Institutes of Health.

\section{Cell culture}

Six-week-old male Fisher 344 rats were obtained from the Ninth People's Hospital Animal Center (Shanghai, China). BMSCs were isolated and cultured following established protocols, as previously described..$^{29} \mathrm{BMSCs}$ were passaged twice before use.

\section{Release profiles and bioactivity of BMP-2 in vitro}

To investigate the release profiles of BMP-2 from nanotube layers, samples of various formulations $(n=4)$ were washed with PBS and then incubated in 6-well plates containing $1 \mathrm{~mL}$ of DMEM (Gibco BRL, Gaithersburg, MD, USA) with 10\% fetal bovine serum (FBS; Hyclone, Logan, UT, USA) per well at $37^{\circ} \mathrm{C}$. The medium was sampled at $1 \mathrm{~h}$ and $1,3,7,10,14$, 21 , and 28 days. At each time point, fresh DMEM was added after the medium was removed. The release of BMP-2 was quantified by analyzing the radioactivity of ${ }^{125} \mathrm{I}$ in the removed DMEM by employing a gamma counter (Shanghai Institute of Nuclear Instrument Factory, Shanghai, China). Finally, all ${ }^{125}$ I counts were normalized to baseline after applying a correction for decay.

To investigate the bioactivity of BMP-2 released from $\mathrm{TiO}_{2}$ nanotubes, releasates of culture from the first 7 days for each sample were collected together, and analysis of alkaline phosphatase (ALP) activity was performed employing the BMSCs. Cells $\left(2 \times 10^{4}\right.$ cells/well $)$ were seeded in 48 -well plates. The concentration of BMP-2 releasates of each group was adjusted to $100 \mathrm{ng} / \mathrm{mL}$ according to the cumulative BMP-2 release of different formulations. Twenty-four hours after seeding, the medium was removed and replaced with DMEM $(0.5 \mathrm{~mL})$ containing $10 \%$ FBS with BMP-2 releasate $(100 \mathrm{ng} / \mathrm{mL})$. The medium alone and the same amount of fresh BMP-2 were employed as the negative (NC) and positive controls, respectively. On days 3, 7, and 14 after incubation, BMSCs were lysed with $0.05 \%$ Triton $^{\mathrm{TM}} \mathrm{X}-100$ $(80 \mu \mathrm{L})$. Then, $20 \mu \mathrm{L}$ of lysate was added to $100 \mu \mathrm{L}$ of disodium $p$-nitrophenylphosphate hexahydrate $(2 \mathrm{mg} / \mathrm{mL})$ and 2-amino-2-methyl-1-propanol (0.75 M). ALP activity was estimated by monitoring the absorbance at $405 \mathrm{~nm}$ after incubation of the mixtures for $30 \mathrm{~min}$ at $37^{\circ} \mathrm{C}$, and then normalized to the total protein content determined by employing bicinchoninic acid assays, as described previously. ${ }^{30}$

\section{Preservation of BMP-2 bioactivity from Lyo/Tre nanotubes}

Samples $(\mathrm{n}=24)$ of $\mathrm{TiO}_{2}$-Lyo-Tre-BMP-2 were stored at $-20^{\circ} \mathrm{C}, 4^{\circ} \mathrm{C}$, or $25^{\circ} \mathrm{C}$. Each sample was kept in a microcentrifuge tube and completely sealed. After storage for 2 or 5 weeks, samples of each group $(n=4)$ were incubated in PBS, and BMP-2 releasate $(100 \mathrm{ng} / \mathrm{mL})$ was collected for the first 7 days to evaluate the BMP-2 bioactivity using ALP activity assays. On day 7, ALP activity was estimated as described in the previous section. To determine the change in BMP-2 bioactivity upon storage at different temperatures and durations, fresh BMP-2 without lyophilization was employed as a standard.

\section{Proliferation of BMSCs exposed to different nanotube formulations}

The proliferation of BMSCs cultured with different groups $\left(\mathrm{TiO}_{2}, \mathrm{TiO}_{2}-\mathrm{BMP}-2, \mathrm{TiO}_{2}\right.$-Lyo-Tre-BMP-2) ( $\mathrm{n}=4$ per group) was investigated in a 6-well Transwell ${ }^{\circledR}$ system $(0.4 \mu \mathrm{m}$; Corning Inc., Corning, NY, USA) on days 1, 3, 7, and 14. Cells were seeded in the lower wells at $10^{5}$ cells $/$ well $(0.5 \mathrm{~mL})$, and the different nanotubes were placed in the upper wells. The culture medium was changed every 2 days. At designated time points, the cells were collected to quantify deoxyribonucleic acid (DNA) contents using the Hoechst 33258 dye (Sigma-Aldrich Co., St Louis, MO, USA) as previously described ${ }^{31}$ Proliferation of BMSCs cocultured with no nanotubes were also assessed.

\section{Effects of BMP-2-loaded nanotubes on the osteogenic differentiation of BMSCs}

The osteogenic differentiation of BMSCs cultured with different formulations $\left(\mathrm{TiO}_{2}, \mathrm{TiO}_{2}-\mathrm{BMP}-2\right.$, and $\mathrm{TiO}_{2}$-LyoTre-BMP-2) ( $\mathrm{n}=4$ per group) was investigated in 6-well Transwell plates $(0.4 \mu \mathrm{m})$. The culture medium was changed every 2 days. Total RNA was extracted using TRIzol ${ }^{\circledR}$ reagent (Invitrogen, Carlsbad, CA, USA) on days 3, 7, and 14. Highly purified gene-specific primers for runt-related transcription factor 2 (Runx), osteopontin $(O P N)$, osteocalcin $(O C N)$, bone sialoprotein $(B S P), A L P$, and the housekeeping gene, GAPDH, were synthesized by Shengong Co., Ltd. 
Table I Nucleotide sequences of primers used for real-time quantitative polymerase chain reaction

\begin{tabular}{|c|c|c|c|c|}
\hline Genes & $\begin{array}{l}\text { Primer sequence }\left(5^{\prime}-3^{\prime}\right) \\
\text { (forward/reverse) }\end{array}$ & $\begin{array}{l}\text { Product } \\
\text { size (bp) }\end{array}$ & $\begin{array}{l}\text { Annealing } \\
\text { temperature }\left({ }^{\circ} \mathrm{C}\right)\end{array}$ & $\begin{array}{l}\text { Accession } \\
\text { number }\end{array}$ \\
\hline \multirow[t]{2}{*}{ Runx2 } & TCTTCCCAAAGCCAGAGCG & 154 & 60 & NM_053470.I \\
\hline & TGCCATTCGAGGTGGTCG & & & \\
\hline \multirow[t]{2}{*}{ OPN } & CCAAGCGTGGAAACACACAGCC & 165 & 60 & NM_0I288I \\
\hline & GGCTTTGGAACTCGCCTGACTG & & & \\
\hline \multirow[t]{2}{*}{ OCN } & CAGTAAGGTGGTGAATAGACTCCG & 172 & 60 & NM_0I34I4.I \\
\hline & GGTGCCATAGATGCGCTTG & & & \\
\hline$B S P$ & TGGATGAACCAAGCGTGGA & 162 & 60 & NM_0I 288I.2 \\
\hline \multirow[t]{3}{*}{$A L P$} & TCGCCTGACTGTCGATAGCA & 172 & 60 & NM_013059.I \\
\hline & GTCCCACAAGAGCCCACAAT & & & \\
\hline & CAACGGCAGAGCCAGGAAT & & & \\
\hline \multirow[t]{2}{*}{ GAPDH } & GGCAAGTTCAACGGCACAGT & 76 & 60 & NM_017008.3 \\
\hline & GCCAGTAGACTCCACGACAT & & & \\
\hline
\end{tabular}

(Shanghai, China; Table 1). The expression levels of each bone-related gene and $G A P D H$ at each time point were determined by real-time polymerase chain reaction (RT-PCR) (7900HT sequence-detection system; Applied Biosystems, Foster City, CA, USA). Data were analyzed using the comparative CT method and the results were expressed as transcript levels using the housekeeping gene $G A P D H$ as the control for normalization. Analysis of endogenous bonerelated gene expression was carried out by calculating the relative expression levels of genes compared with those in BMSCs cultured with $\mathrm{TiO}_{2}$ nanotubes. ${ }^{32}$

\section{Rat femur defect model for evaluating bone regeneration}

Surgical procedure

The right femurs of 48 male Fisher 344 rats were implanted with the following 8 groups of implants ( $n=6$ rats per group): $\mathrm{TiO}_{2}, \mathrm{TiO}_{2}-0.3 \mu \mathrm{g}$ BMP-2, $\mathrm{TiO}_{2}-0.5 \mu \mathrm{g} \mathrm{BMP}-2, \mathrm{TiO}_{2}-1.0 \mu \mathrm{g}$ BMP-2, $\mathrm{TiO}_{2}$-Lyo-Tre, $\mathrm{TiO}_{2}$-Lyo-Tre-0.3 $\mu \mathrm{g}$ BMP-2, $\mathrm{TiO}_{2}-$ Lyo-Tre-0.5 $\mu$ g BMP-2, and $\mathrm{TiO}_{2}$-Lyo-Tre-1.0 $\mu \mathrm{g}$ BMP-2.

\section{Sequential fluorescent labeling}

A polychrome sequential fluorescent labeling method was performed to assess new bone formation and mineralization around the implants as described previously. ${ }^{33}$ Briefly, rats were injected intraperitoneally with $30 \mathrm{mg} / \mathrm{kg}$ Alizarin Red $\mathrm{S}$ (Sigma-Aldrich Co.) and $20 \mathrm{mg} / \mathrm{kg}$ calcein (Sigma-Aldrich Co.) at 2 and 6 weeks after implantation, respectively.

\section{Specimen preparation}

Eight weeks after surgery, all rats were sacrificed. The right femurs were harvested and then fixed in 10\% buffered formaldehyde for micro-CT and histomorphometric observations.

\section{Micro-CT assay}

The fixed specimens were imaged and detected employing a GE eXplore Locus SP Micro-CT (GE Healthcare, Chicago, IL, USA) to visualize the new bone formed around the implants. The parameters were set at $80 \mu \mathrm{A}$ current and $80 \mathrm{kV}$ voltage, with an exposure time of 3,000 ms. The 3D images were reconstructed using GEHC MicroView software (GE Healthcare, London, UK) after scanning. To obtain the parameters of bone mineral density and bone volume fraction (bone volume/ total volume) of the newly formed bone around the implant, a region with a radius of $0.5 \mathrm{~mm}$ from the implant surface within the bone marrow cavity was chosen for analysis.

\section{Histomorphometric observations}

All samples were dehydrated in ascending concentrations of ethanol $50 \%-100 \%$, and then embedded in polymethylmetacrylate for undecalcified sectioning. Fully polymerized specimens were sectioned into $150-\mu \mathrm{m}$-thick sections using a Leica SP1600 saw microtome (Leica, Wetzlar, Germany) in an orientation nearly parallel to the long axis of the implants. All sections were subsequently ground and polished to a final thickness of $\sim 30 \mu \mathrm{m}$ for Alizarin Red S and calcein fluorescence imaging. Finally, the samples were stained with van Gieson's picrofuchsin for subsequent histological analysis. Image-Pro Plus 6.0 (Media Cybernetics, Rockville, MD, USA) was used to evaluate the areas of new bone formed around the implants.

\section{Statistical analysis}

Statistical comparisons were carried out using one-way analysis of variance and Student-Newman-Keuls test. All statistical analyses were performed using SAS 8.2 (SAS Institute Inc., Cary, NC, USA). All data are reported as 
mean $\pm \mathrm{SD}$. Differences with $p$-values of $<0.05$ were considered significant.

\section{Results}

\section{Surface observations and characterizations}

Surface views of $\mathrm{TiO}_{2}$ nanotubes are shown in Figure 1A, and those of $\mathrm{TiO}_{2}$-BMP-2 (left) and $\mathrm{TiO}_{2}$-Lyo-Tre-BMP-2 (right) are shown in Figure 1B. The anodized $\mathrm{TiO}_{2}$ nanotube layer was distributed uniformly over the substrate with a diameter and length of $\sim 100$ and $400 \mathrm{~nm}$, respectively. Relatively little amorphous glassy matrix remained on the surface of $\mathrm{TiO}_{2}$-BMP-2, while a much larger amount was observed on the surface of $\mathrm{TiO}_{2}$-Lyo-Tre-BMP-2. The results for surface chemical characterization are shown in Figure 1C. The characteristic infrared (IR) bands were found at $600-710 \mathrm{~cm}^{-1}$ for all the groups; the absorption peaks at 1,690 and 3,400 $\mathrm{cm}^{-1}$ were only seen in groups of $\mathrm{TiO}_{2}$ and $\mathrm{TiO}_{2}-\mathrm{BMP}-2$.

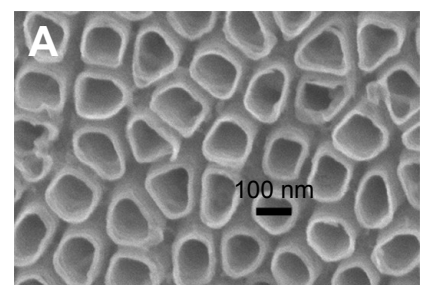

C

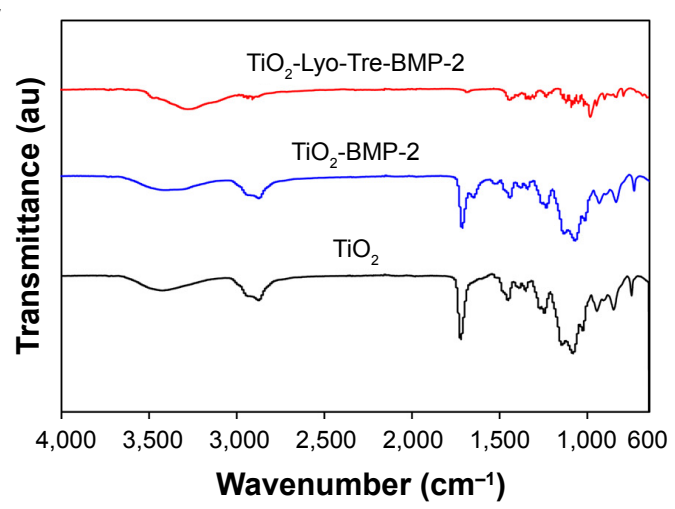

E

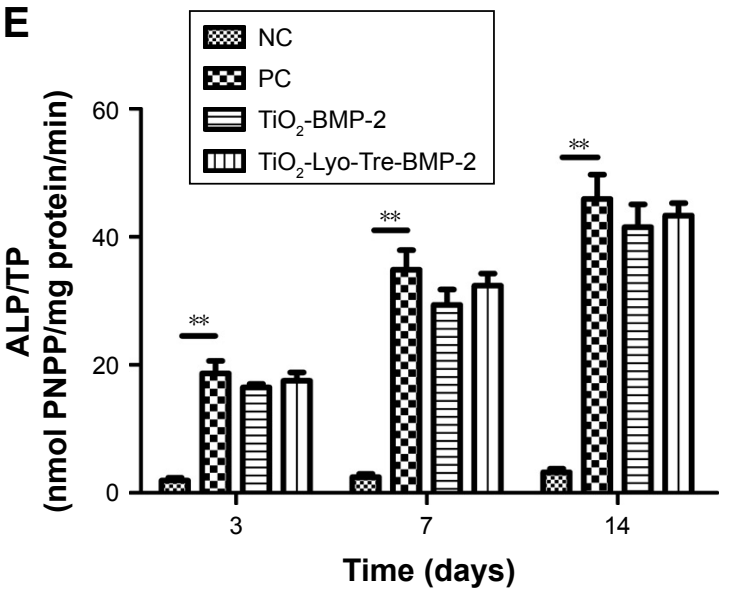

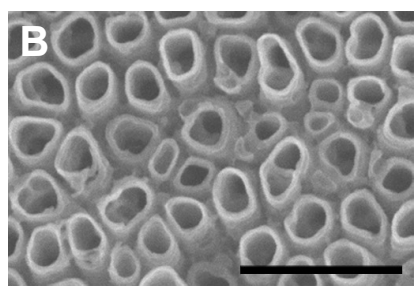
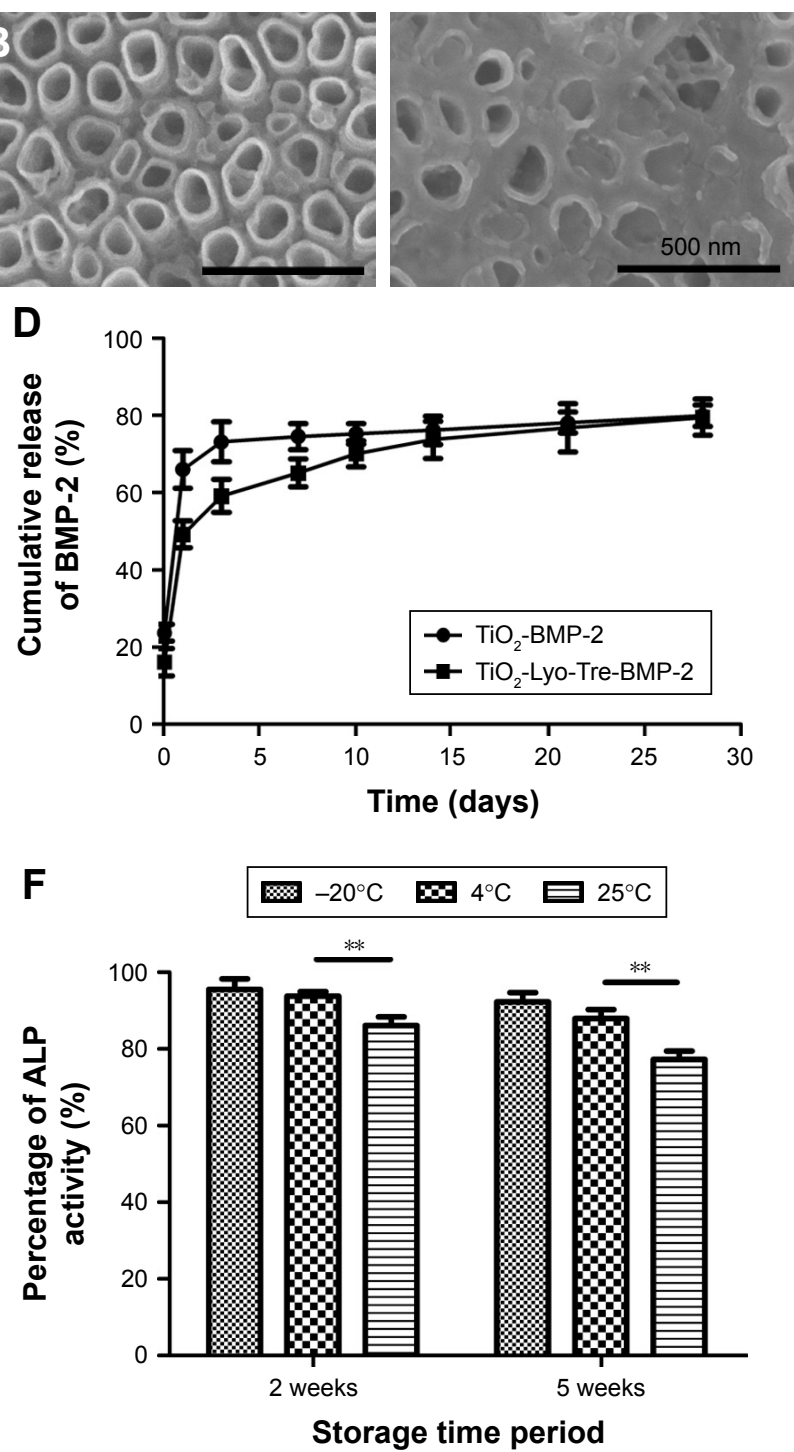

Figure I Characterization of $\mathrm{TiO}_{2}$ nanotubes and surface morphology, chemical characterization, BMP-2 release, and ALP activity assay in BMP-2-loaded nanotubes, and analysis of the stability of lyophilized BMP-2 with trehalose.

Notes: SEM images of $(\mathbf{A}) \mathrm{TiO}_{2}$ nanotubes and (B) $\mathrm{TiO}_{2}-\mathrm{BMP}-2$ (left), TiO - -Lyo-Tre-BMP-2 (right). (C) FTIR spectra of TiO , TiO $_{2}-\mathrm{BMP}-2$, and TiO - Lyo-Tre-BMP-2. (D) BMP-2 release profiles of $\mathrm{TiO}_{2}-\mathrm{BMP}-2$ and $\mathrm{TiO}_{2}$-Lyo-Tre-BMP-2. (E) ALP activity assays of BMSCs cocultured with $\mathrm{BMP}^{-2}$ releasates from TiO $-\mathrm{BMP}-2$ and TiO - -LyoTre-BMP-2 on days 3, 7, and I4. Fresh BMP-2 solution ( $100 \mathrm{ng} / \mathrm{mL})$ was used as the PC, and medium only was used as the NC. (F) Stability of lyophilized BMP-2 on TiO, nanotubes with trehalose. Evaluation of the percentage of BMP-2 bioactivity in lyophilized $\mathrm{TiO}_{2}$ nanotubes with trehalose under different temperature conditions. After 2 or 5 weeks of storage, $100 \mathrm{ng} / \mathrm{mL}$ of BMP-2 releasate from $\mathrm{TiO}_{2}$-Lyo-Tre-BMP-2 was collected for ALP activity assays. The same amount of fresh BMP-2 was compared as a standard for the ALP activity assay to determine the changes in protein bioactivity. ${ }^{* * i n d i c a t e s ~ s i g n i f i c a n t ~ d i f f e r e n c e s ~ b e t w e e n ~ g r o u p s ~}(p<0.0 \mathrm{I})$.

Abbreviations: ALP, alkaline phosphatase; BMP-2, bone morphogenetic protein-2; FTIR, Fourier transform infrared spectroscopy; Lyo, lyophilization; NC, negative control; PC, positive control; SEM, scanning electron microscopy; Tre, trehalose; TP, total protein; PNPP, p-nitrophenylphosphate. 


\section{In vitro release profiles of BMP-2 from $\mathrm{TiO}_{2}$ nanotubes}

The in vitro release kinetics of BMP-2 for different groups are shown in Figure 1D. BMP-2 was released from $\mathrm{TiO}_{2}-$ Lyo-Tre-BMP-2 nanotubes in a sustained manner during the experiment; however, $\mathrm{TiO}_{2}$-BMP-2 nanotubes exhibited an initial burst of BMP-2 release, followed by a slow release over days 3-28. Approximately $73 \%$ of the BMP-2 loaded on $\mathrm{TiO}_{2}$ nanotubes was released over the first 3 days, whereas the equivalent amount of BMP-2 was released from $\mathrm{TiO}_{2}$ Lyo-Tre nanotubes over a period of 14 days.

\section{Bioactivity of BMP-2 released from $\mathrm{TiO}_{2}$ nanotubes}

The bioactivities of BMP-2 released from different formulations are shown in Figure 1E. The equivalent amount of BMP-2 releasates from $\mathrm{TiO}_{2}$-BMP-2 and $\mathrm{TiO}_{2}$-Lyo-TreBMP-2 nanotubes and from fresh BMP-2 exhibited significantly enhanced ALP activity compared with the $\mathrm{NC}(p<0.01)$ on days 3,7 , and 14 . However, no significant differences were found in the bioactivities of BMP-2 among the releasates from the 3 formulations at each time point.

\section{Stability of BMP-2 with Lyo/Tre}

The bioactivity of BMP-2 loaded on $\mathrm{TiO}_{2}$-Lyo-Tre-BMP-2 nanotubes under different storage temperatures and times are shown in Figure $1 \mathrm{~F}$. After 2 weeks of storage at $-20^{\circ} \mathrm{C}$ and $4^{\circ} \mathrm{C}$ and after 5 weeks of storage at $-20^{\circ} \mathrm{C}$, over $90 \%$ of the bioactivity of BMP-2 remained compared with that of fresh BMP-2. After 2 weeks of storage at $25^{\circ} \mathrm{C}$ and 5 weeks of storage at $4^{\circ} \mathrm{C}, \mathrm{BMP}-2$ retained about $85 \%$ of its bioactivity. After 5 weeks of storage at $25^{\circ} \mathrm{C}$, the bioactivity of BMP-2 decreased to about $75 \%$. The bioactivities of BMP-2 loaded on the $\mathrm{TiO}_{2}$-Lyo-Tre-BMP-2 nanotubes stored at $25^{\circ} \mathrm{C}$ for 2 or 5 weeks were significantly lower than those of the $\mathrm{TiO}_{2}$ Lyo-Tre-BMP-2 nanotubes stored at $-20^{\circ} \mathrm{C}$ and $4{ }^{\circ} \mathrm{C}$ during the same time frame $(p<0.01)$.

\section{Effects of culture with nanotubes on the proliferation of BMSCs}

The proliferation of BMSCs cultured with medium only, $\mathrm{TiO}_{2}, \mathrm{TiO}_{2}$-BMP-2, or $\mathrm{TiO}_{2}$-Lyo-Tre-BMP-2, on days 1, 3, 7, and 14, was analyzed with a DNA-detection assay (Figure 2). The number of BMSCs following coculture with different groups increased over time and was nearly equal at each time point, indicating that the various nanotube formulations have no cytotoxicity.

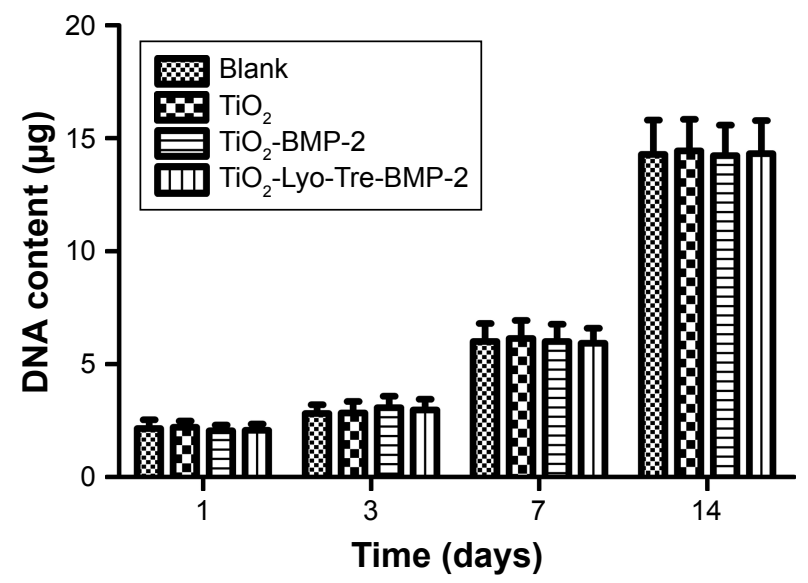

Figure 2 Effects of culture with nanotubes on the proliferation of BMSCs. Note: A DNA-based cell proliferation assay was used to analyze BMSCs cocultured with different nanotube types for I, 3, 7, and I4 days.

Abbreviations: BMSCs, bone marrow stromal cells; BMP-2, bone morphogenetic protein-2; Lyo, lyophilization; Tre, trehalose.

\section{Effects of culture with nanotubes on the osteogenic differentiation of BMSCs}

The osteogenic differentiation of BMSCs cultured with different nanotube formulations $\left(\mathrm{TiO}_{2}, \mathrm{TiO}_{2}-\mathrm{BMP}-2\right.$, and $\mathrm{TiO}_{2}$-Lyo-Tre-BMP-2) was determined by RT quantitative PCR (Figure 3A-E). For BMSCs cultured with $\mathrm{TiO}_{2}$-LyoTre-BMP-2 nanotubes, the expression level of Runx2 mRNA was first upregulated at day 3 (9.7-fold), which increased continuously from days 7 (16.2-fold) to 14 (19.8-fold) (Figure 3A); $O P N$ expression showed a dramatical rise from days 3 (24.8-fold) to 7 (56.2-fold) and then increased slightly from days 7 to 14 (64-fold) (Figure 3B); OCN, BSP, and $A L P$ mRNA levels increased slightly at day 3 (4.9-, 16.9-, and 4.2-fold, respectively), followed by a marked increase between days 7 (11.4-, 38.7-, and 7.6-fold, respectively) and 14 (41.5-, 135.1-, and 18.3-fold, respectively) (Figure 3C-E). For BMSCs cultured with $\mathrm{TiO}_{2}$-BMP-2 nanotubes, the expressions of Runx2, OPN, OCN, BSP, and ALP mRNAs were similar to those in BMSCs cultured with $\mathrm{TiO}_{2}$-LyoTre-BMP-2 nanotubes; however, the fold increases were significantly lower on day 14 (12.2-, 39.9-, 20.1-, 68.3-, and 9.9-fold, respectively) $(p<0.01)$. The expression levels of Runx2 (4.9- and 9.4-fold-, respectively) and $O P N$ (16.2- and 33.5-folds, respectively) mRNAs were also significantly lower than those in BMSCs cultured with $\mathrm{TiO}_{2}$-Lyo-TreBMP-2 nanotubes on days 3 and $7(p<0.01)$. Overall, the expression levels of osteogenic markers were significantly lower in BMSCs cultured with $\mathrm{TiO}_{2}$ nanotubes than in those cultured with the other 2 types of nanotubes at each time point $(p<0.01)$. 
A

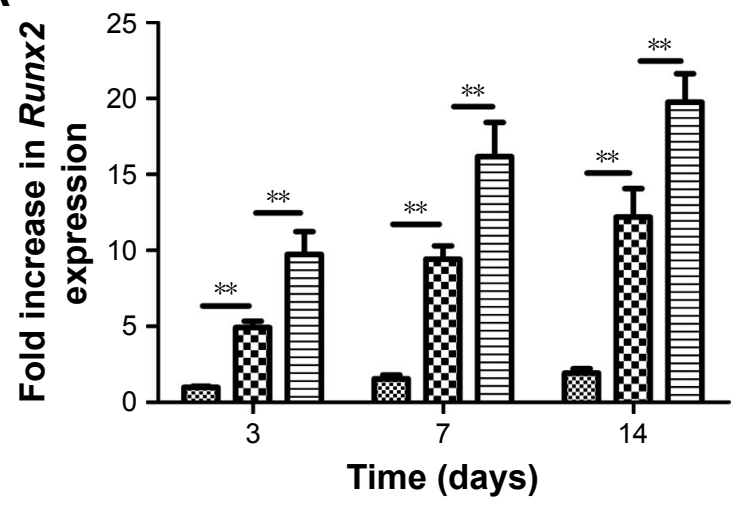

C

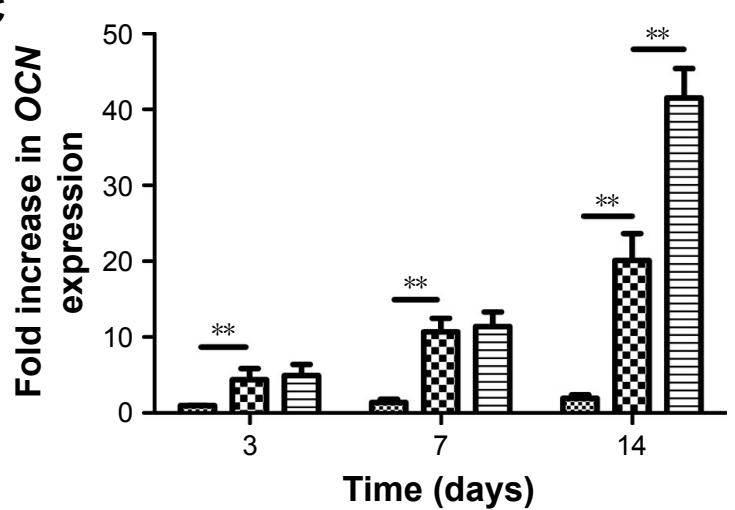

B

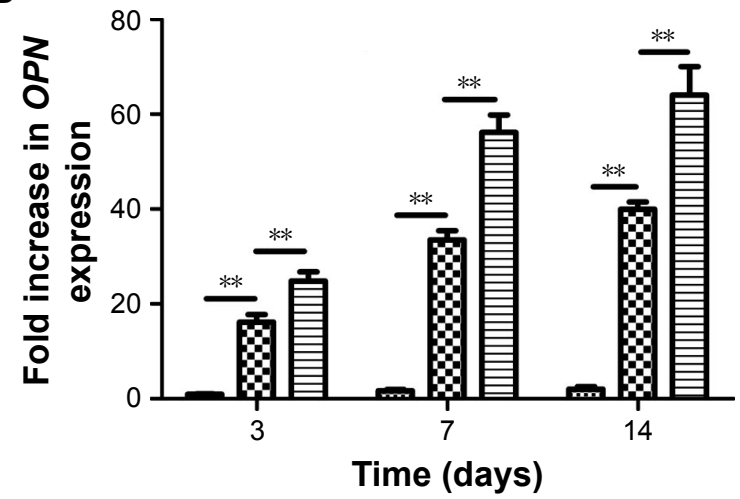

D

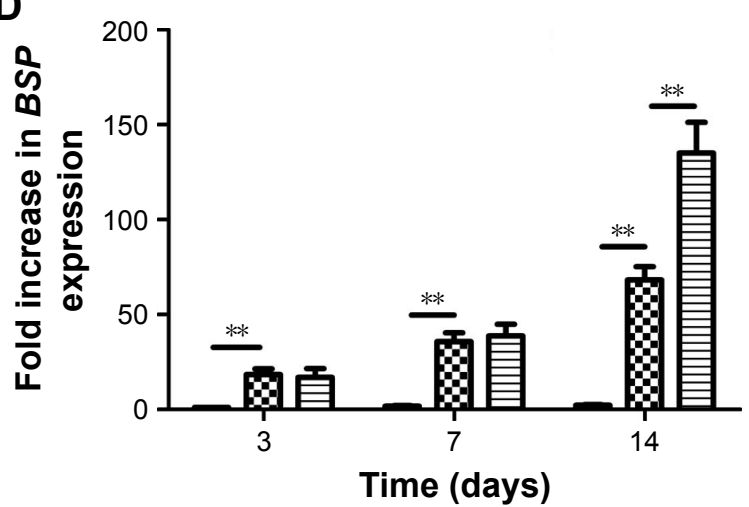

E

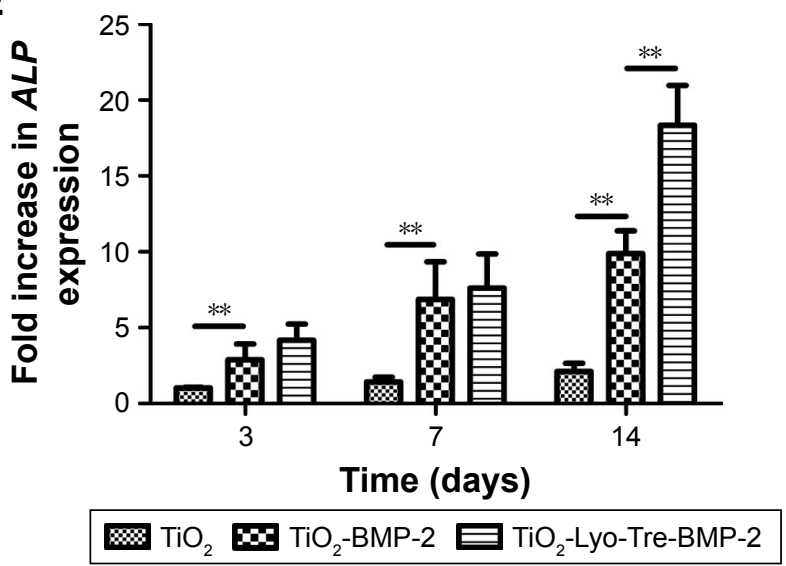

Figure 3 Effects of different formulations on the osteogenic differentiation of BMSCs.

Notes: Real-time quantitative polymerase chain reaction analysis of the expression of (A) Runx2, (B) OPN, (C) OCN, (D) BSP, and (E) ALP in BMSCs cocultured with TiO 2 alone, $\mathrm{TiO}_{2}$-BMP-2, and $\mathrm{TiO}_{2}$-Lyo-Tre-BMP-2 on days 3, 7, and I4. $* *$ indicates significant differences between groups $(p<0.0 \mathrm{I})$.

Abbreviations: ALP, alkaline phosphatase; BMSCs, bone marrow stromal cells; BSP, bone sialoprotein; BMP-2, bone morphogenetic protein-2; Lyo, lyophilization; $O C N$, osteocalcin; OPN, osteopontin; Runx2, runt-related transcription factor 2; Tre, trehalose.

\section{In vivo bone formation around implants}

Next, we examined the ability of BMP-2 delivered employing lyophilized $\mathrm{TiO}_{2}$ nanotubes with additional trehalose $\left(\mathrm{TiO}_{2}-\right.$ Lyo-Tre) to reduce the BMP-2 dose needed for in vivo bone regeneration (Figures 4-6). The ability of BMP-2 to induce bone regeneration depends on the delivery system used. Micro-CT analysis (Figure 4), sequential fluorescent labeling analysis (Figure 5), and histological analysis (Figure 6) all revealed that various doses of BMP-2 delivered employing $\mathrm{TiO}_{2}$-Lyo-Tre led to significantly greater new bone formation around the implants than that achieved employing $\mathrm{TiO}_{2}$ alone. The formation of new bone increased with the increase in BMP-2 dose in both groups. The newly formed bone areas in rats implanted with $\mathrm{TiO}_{2}$-Lyo-Tre-BMP-2 nanotubes containing 0.3 or $0.5 \mu \mathrm{g}$ BMP-2 were approximately equal to those implanted with $\mathrm{TiO}_{2}$-BMP-2 nanotubes containing 
A

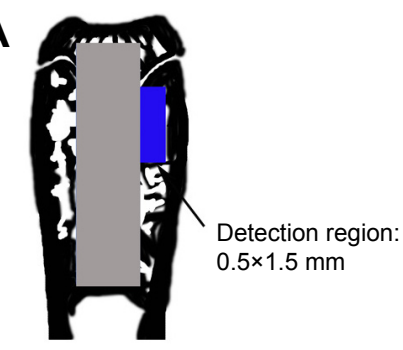

B

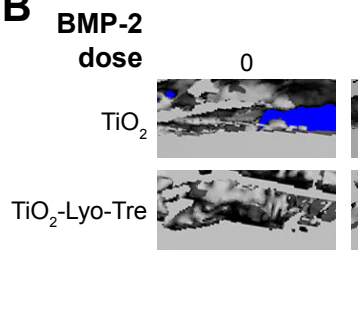

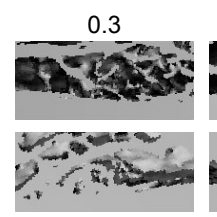

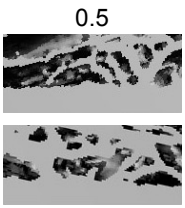

C

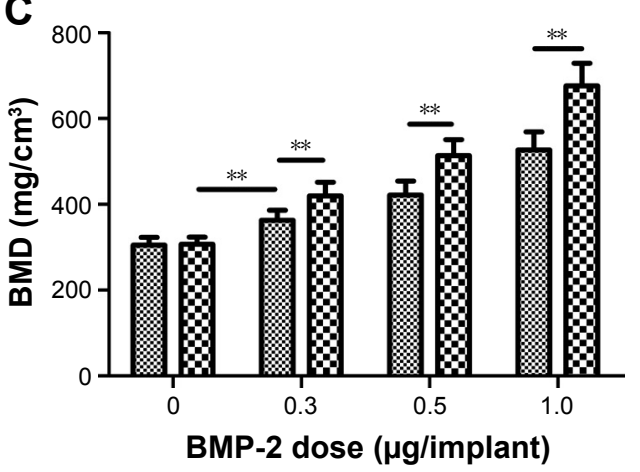

D

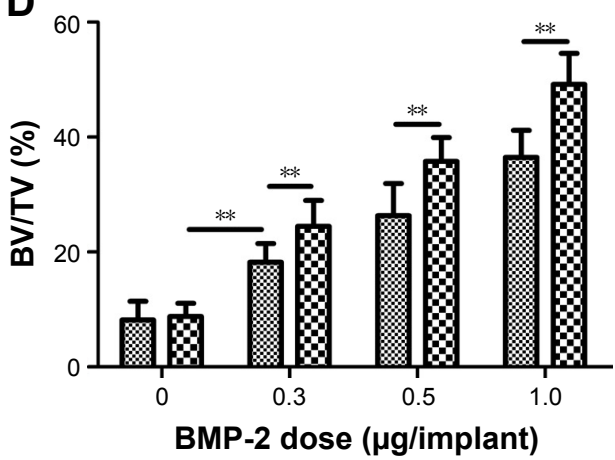

$\mathbb{R} \mathrm{TiO}_{2} \quad \mathrm{TiO}_{2}$-Lyo-Tre

Figure 4 Micro-CT evaluation and morphometric analysis of samples collected at week 8 after surgery.

Notes: (A) The image shows the blue rectangle region, which was selected to evaluate new bone formation around the implants. (B) Representative 3D micro-CT images of different groups. Analysis of $(\mathbf{C})$ bone mineral density and (D) bone volume/total volume by micro-CT for each group. ${ }^{*}$ indicates significant differences between groups $(p<0.01)$.

Abbreviations: BMD, bone mineral density; BMP-2, bone morphogenetic protein-2; BV/TV, bone volume/total volume; Lyo, lyophilization; Tre, trehalose.

0.5 or $1.0 \mu \mathrm{g}$ BMP-2, respectively, indicating that delivery of a lower dose of BMP-2 by $\mathrm{TiO}_{2}$-Lyo-Tre nanotubes led to new bone formation similar to that of delivery of a higher dose of BMP-2 by $\mathrm{TiO}_{2}$ nanotubes alone.

\section{Discussion}

BMP-2 has been used extensively to induce new bone formation; ${ }^{2-5}$ however, clinical application of BMP-2 requires high doses, ${ }^{6,7}$ which are associated with increased treatment costs and unwanted side effects, such as excessive immune responses, wound complications, and bone resorption. ${ }^{8-10,34}$ Therefore, an appropriate delivery system for reducing the dose of BMP-2 for bone regeneration is required. Recent studies have mainly focused on organic, inorganic, and synthetic carrier scaffolds. These carrier scaffolds include collagen sponges,${ }^{35}$ calcium phosphate-based cements,${ }^{36}$ polylactic acid, polyglycolide, and their copolymer..$^{37}$ Although there are many suitable delivery carriers available, the optimal scaffold for BMP-2 delivery remains to be identified. Furthermore, our previous works have shown that BMP-2 or Lenti-BMP-2 lyophilized on scaffolds with trehalose enable long-term release of BMP-2 while retaining protein activity, thereby enhancing osteogenesis. ${ }^{25,26}$ However, it was not known whether delivery of BMP-2 based on Lyo/Tre could reduce the dose of BMP-2 required for effective bone regeneration. Here, we hypothesize that delivery systems for BMP-2 based on Lyo/Tre may be applied as an alternative method to develop a novel delivery system for the reduction of BMP-2 dose. In this study, we developed a novel delivery system based on Lyo/Tre to achieve efficient bone formation. The effects of these nanotubes on BMSC differentiation in vitro were demonstrated, and their implantation in rat femurs yielded significantly enhanced bone formation in vivo. Thus, our data provide important insights into the applications of $\mathrm{TiO}_{2}$ nanotubes lyophilized with trehalose in bone regeneration and delivery of BMP-2.

A much larger amount of amorphous glassy matrix was observed on the surface of $\mathrm{TiO}_{2}$-Lyo-Tre-BMP-2 than on that of $\mathrm{TiO}_{2}-\mathrm{BMP}-2$. This discrepancy between the 2 formulations under SEM observation might be attributed to trehalose. Each foil ( $\mathrm{TiO}_{2}$-BMP-2, $\mathrm{TiO}_{2}$-Lyo-Tre-BMP-2) was loaded with $6 \mu \mathrm{g}$ of BMP-2, while for $\mathrm{TiO}_{2}$-Lyo-Tre-BMP- $2,3 \times 10^{-5} \mathrm{~mol}$ $\left(1.1 \times 10^{4} \mu \mathrm{g}\right)$ trehalose was added as a protectant.

As shown in the FTIR spectra of different formulations, the characteristic IR bands were found at $600-710 \mathrm{~cm}^{-1}$ for all the groups, proving the existence of $\mathrm{Ti}-\mathrm{O}$ bonds in the $\mathrm{TiO}_{2}$ lattice. However, the absorption peaks at 1,690 and $3,400 \mathrm{~cm}^{-1}$ were only found in groups of $\mathrm{TiO}_{2}$ and $\mathrm{TiO}_{2}$-BMP-2, 

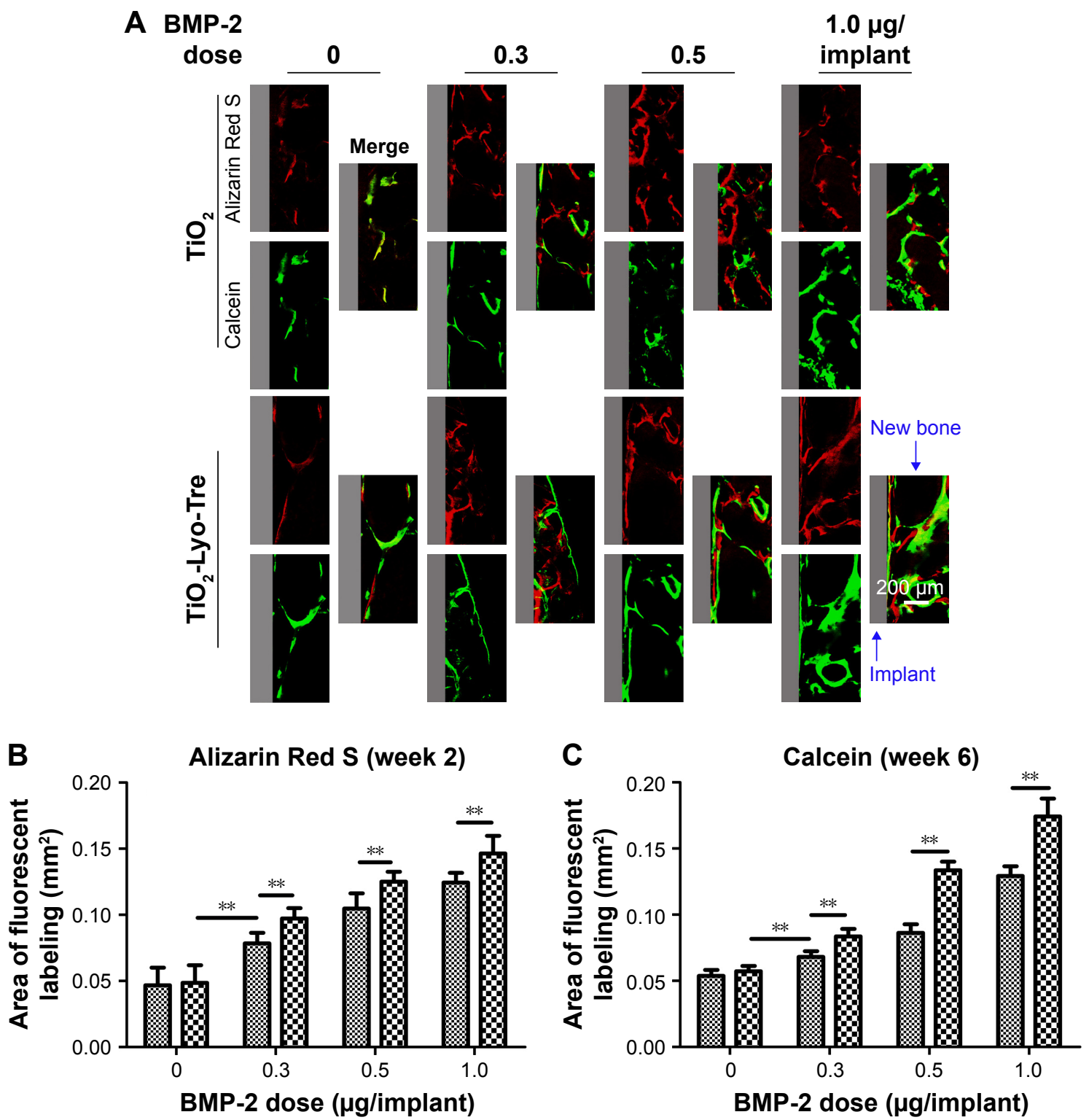

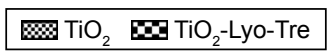

Figure 5 Sequential fluorescent labeling and histomorphometric analysis of the fluorochrome area.

Notes: (A) New bone formation and mineralization were determined by Alizarin Red S (red) and calcein (green) staining, indicating the mineralization level at week 2 and week 6 after operation, respectively. (B and C) Histomorphometric analysis of the area of bone stained with the two fluorochromes. **indicates significant differences between groups $(p<0.01)$.

Abbreviations: BMP-2, bone morphogenetic protein-2; Lyo, lyophilization; Tre, trehalose.

which were attributed to the bending mode of $\mathrm{OH}$ and the stretching vibration of surface hydroxyl and absorbed water, ${ }^{38}$ indicating that no water molecules existed on the surface of $\mathrm{TiO}_{2}$-Lyo-Tre-BMP-2 nanotubes. These may be attributed to the lyophilization process.

As a BMP-2 delivery system, $\mathrm{TiO}_{2}$-Lyo-Tre-BMP-2 nanotubes facilitated sustained release, persistent bioactivity, and higher stability of BMP-2; these features are important for enhanced bone regeneration. Compared with the bolus release of BMP-2 from $\mathrm{TiO}_{2}-\mathrm{BMP}-2$ nanotubes,
$\mathrm{TiO}_{2}$-Lyo-Tre-BMP-2 nanotubes were associated with slow, prolonged BMP-2 release. This release kinetics of difference between the 2 formulations could be due to the high binding affinity of BMP-2 with titanium-based materials, caused by lyophilization. ${ }^{39}$ Additionally, we found that the bioactivity of BMP-2 released from $\mathrm{TiO}_{2}$-Lyo-Tre-BMP-2 nanotubes was preserved, similar to that of fresh BMP-2. Although adsorbed BMP-2 also maintained its bioactivity, the osteogenesis of BMSCs cultured with $\mathrm{TiO}_{2}$-BMP-2 was statistically lower than that of BMSCs cultured with $\mathrm{TiO}_{2}$-Lyo-Tre-BMP-2. 

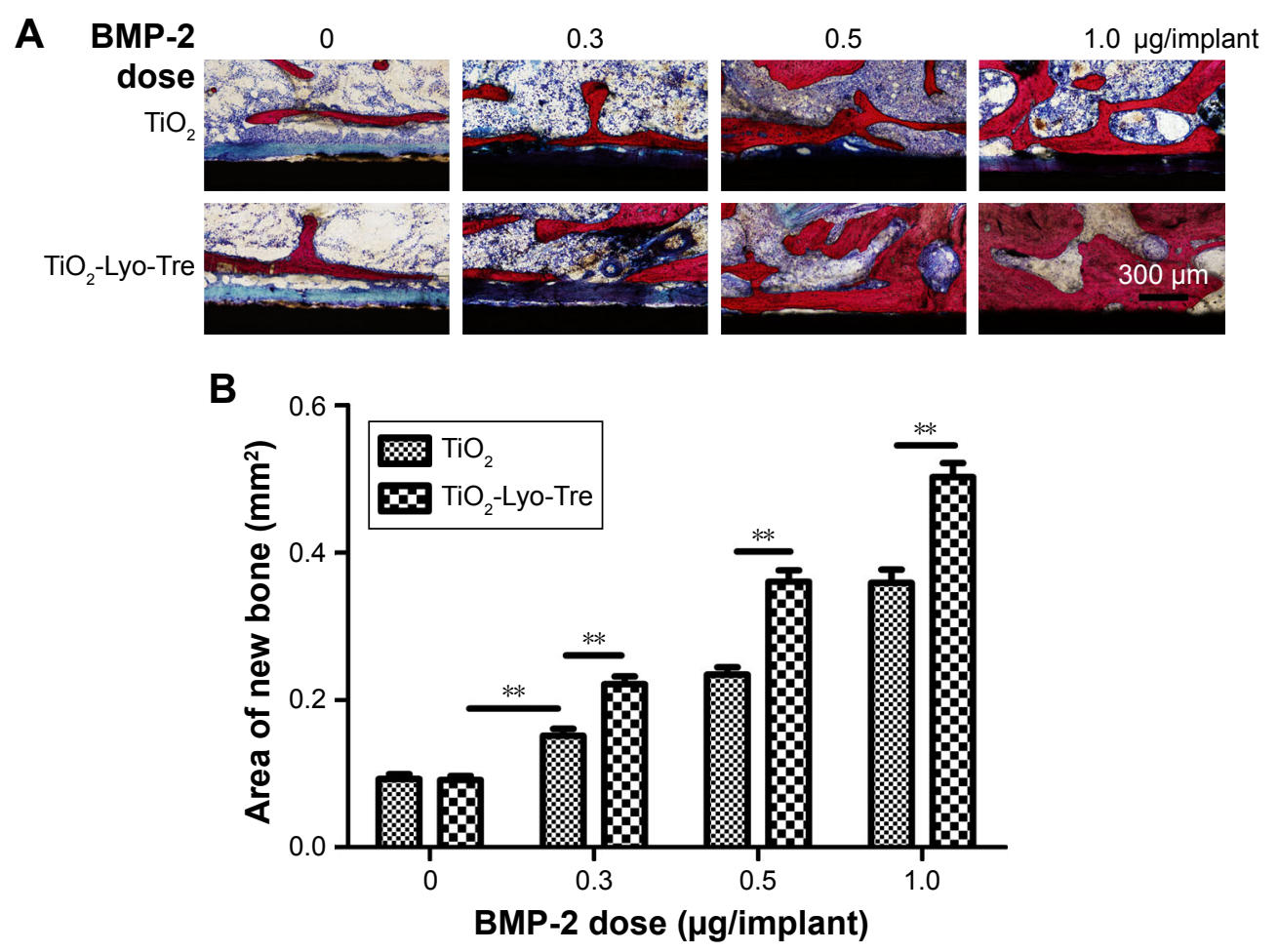

Figure 6 Histological observations and histomorphometric measurements.

Notes: (A) Histological observations of the undecalcified sections stained with Van Gieson's picrofuchsin in the same region as micro-CT and fluorescent observations. (B) Results of newly formed bone area from the histomorphmetric measurements. **indicates significant differences between groups $(p<0.0 \mathrm{I})$.

Abbreviations: BMP-2, bone morphogenetic protein-2; Lyo, lyophilization; Tre, trehalose.

This result indicates that the BMP-2 release profiles play a key role in promoting osteogenic differentiation of cells. For promotion of the osteogenesis of BMSCs, release of BMP-2 in a sustained manner is more effective. Accordingly, sustained release of BMP-2 with maintained bioactivity has been shown to improve the osteogenic ability of BMP-2.40,41 Moreover, long-term delivery of BMP-2 over a period of 4 weeks was shown to induce a significantly higher amount of newly-formed bone than the same quantity of BMP-2 released over 3 days. ${ }^{42,43}$ Other research studies have found that BMP-2 does not induce a significant amount of new bone formation when released over $<7$ days. ${ }^{44,45}$ These results may be partially explained by the observation that sustained release of BMP-2 can enhance the long-term osteogenesis and migration of progenitor cells or mesenchymal stem cells for several weeks; these processes are necessary for successful new bone formation. ${ }^{46}$

Growth factors are inactivated easily by storage at different temperatures and for different durations; however, few studies have been performed to assess the bioactivities of growth factors that were loaded onto delivery systems for bone regeneration. In 1 study, $60 \%$ of the bioactivity of growth factors absorbed on a Ca-P cement scaffold was preserved after storage at room temperature for 5 weeks. However, the release profiles of the loaded growth factors were not explored. ${ }^{47}$ In the present study, our delivery system based on Lyo/Tre was found to preserve the bioactivity of BMP-2 during the preparation process of the implant, as well as to facilitate the maintenance of over $75 \%$ of BMP-2 bioactivity at $25^{\circ} \mathrm{C}$ for at least 5 weeks. By retaining the stability of bioactive growth factors, new delivery systems based on Lyo/Tre may improve the capacity for regeneration of new bone tissue in various clinical applications.

Compared with $\mathrm{TiO}_{2}-\mathrm{BMP}-2$ nanotubes, $\mathrm{TiO}_{2}$-LyoTre-BMP-2 nanotubes promoted the sustained release, maintained bioactivity, and stability of BMP-2; these effects were thought to be conferred by Lyo/Tre. Lyophilization is an effective method for increasing the physical and chemical stability of biomolecules. However, some growth factors may undergo irreversible structural changes during the freezing and drying process, resulting in inactivation of the biomolecule. ${ }^{19}$ In order to prevent such inactivation, we and others have used trehalose as a protectant. ${ }^{22}$ The ionic interactions between positively charged cavities in BMP-2 molecules and negatively charged polysaccharide chains in trehalose molecules increase the binding affinity between BMP-2 and trehalose. The lyophilization process further generates an enhanced high-binding affinity between BMP-2/Tre and Ti-based materials. This synergistic effect 
may be responsible for the sustained release of BMP-2 observed from $\mathrm{TiO}_{2}$-Lyo-Tre-BMP-2 nanotubes.

The bone formation efficacy of BMP-2 delivered by $\mathrm{TiO}_{2}-$ Lyo-Tre-BMP-2 nanotubes was superior to that of BMP-2 delivered by $\mathrm{TiO}_{2}-\mathrm{BMP}-2$ nanotubes. Doses of 0.3 and $0.5 \mu \mathrm{g}$ BMP-2 delivered by $\mathrm{TiO}_{2}$-Lyo-Tre-BMP-2 elicited bone formation efficacies similar to those of 0.5 and $1.0 \mu \mathrm{g}$ BMP-2 delivered by $\mathrm{TiO}_{2}$-BMP-2 nanotubes, respectively. Thus, the enhanced bone regeneration capacity of BMP-2 delivered using a system based on Lyo/Tre is expected to permit the use of lower doses of BMP-2 for successful new bone formation, thereby reducing the severity of side effects induced by high doses of BMP-2.

\section{Conclusion}

In summary, delivery of BMP-2 using $\mathrm{TiO}_{2}$-Lyo-Tre nanotubes promoted greater osteogenic differentiation of BMSCs in vitro and enhanced bone regeneration in vivo than delivery of BMP-2 using $\mathrm{TiO}_{2}$ nanotubes alone. Importantly, BMP-2 delivery employing the present Lyo/Tre-based system could reduce the dose of BMP-2 needed for effective bone regeneration through the sustained release, persistent bioactivity, and better stability of BMP-2. Therefore, delivery of BMP-2 using the Lyo/Tre-based system may be an effective method for reducing the required dose of BMP-2 for bone regeneration and suppressing unwanted side effects induced by the administration of high doses of BMP-2.

\section{Acknowledgment}

Financial support from the National Natural Science Foundation of China (81200815, 81371164, and 81470765), Scientific and Technological Innovation Action Plan of Shanghai Science and Technology Commission (17441902000).

\section{Disclosure}

The authors report no conflicts of interest in this work.

\section{References}

1. Reddi AH. BMPs: from bone morphogenetic proteins to body morphogenetic proteins. Cytokine Growth Factor Rev. 2005;16(3):249-250.

2. Termaat MF, Den Boer FC, Bakker FC, Patka P, Haarman HJ. Bone morphogenetic proteins. Development and clinical efficacy in the treatment of fractures and bone defects. J Bone Joint Surg Am. 2005;87(6): 1367-1378.

3. Govender S, Csimma C, Genant HK, et al. Recombinant human bone morphogenetic protein- 2 for treatment of open tibial fractures: a prospective, controlled, randomized study of four hundred and fifty patients. J Bone Joint Surg Am. 2002;84-A(12):2123-2134.

4. Kanakaris NK, Giannoudis PV. Clinical applications of bone morphogenetic proteins: current evidence. J Surg Orthop Adv. 2008;17(3): $133-146$.
5. Poynton AR, Lane JM. Safety profile for the clinical use of bone morphogenetic proteins in the spine. Spine. 2002;27(16 Suppl 1): $\mathrm{S} 40-\mathrm{S} 48$.

6. Shields LB, Raque GH, Glassman SD, et al. Adverse effects associated with high-dose recombinant human bone morphogenetic protein-2 use in anterior cervical spine fusion. Spine. 2006;31(5):542-547.

7. Mont MA, Ragland PS, Biggins B, et al. Use of bone morphogenetic proteins for musculoskeletal applications. An overview. J Bone Joint Surg Am. 2004;86(A Suppl 2):41-55.

8. James AW, LaChaud G, Shen J, et al. A review of the clinical side effects of bone morphogenetic protein-2. Tissue Eng Part B Rev. 2016; 22(4):284-297.

9. Carragee EJ, Hurwitz EL, Weiner BK. A critical review of recombinant human bone morphogenetic protein-2 trials in spinal surgery: emerging safety concerns and lessons learned. Spine J. 2011;11(6):471-491.

10. Lewandrowski KU, Nanson C, Calderon R. Vertebral osteolysis after posterior interbody lumbar fusion with recombinant human bone morphogenetic protein 2: a report of five cases. Spine J. 2007;7(5): 609-614.

11. Yang HS, La WG, Bhang SH, Jeon JY, Lee JH, Kim BS. Heparinconjugated fibrin as an injectable system for sustained delivery of bone morphogenetic protein-2. Tissue Eng Part A. 2010;16(4):1225-1233.

12. Yamamoto M, Takahashi Y, Tabata Y. Enhanced bone regeneration at a segmental bone defect by controlled release of bone morphogenetic protein-2 from a biodegradable hydrogel. Tissue Eng. 2006; 12(5):1305-1311.

13. Oh S, Daraio C, Chen LH, Pisanic TR, Finones RR, Jin S. Significantly accelerated osteoblast cell growth on aligned $\mathrm{TiO} 2$ nanotubes. J Biomed Mater Res A. 2006;78(1):97-103.

14. Bjursten LM, Rasmusson L, Oh S, Smith GC, Brammer KS, Jin S. Titanium dioxide nanotubes enhance bone bonding in vivo. $J$ Biomed Mater Res A. 2010;92(3):1218-1224.

15. Sun S, Yu W, Zhang Y, Zhang F. Increased preosteoblast adhesion and osteogenic gene expression on $\mathrm{TiO} 2$ nanotubes modified with KRSR. J Mater Sci Mater Med. 2013;24(4):1079-1091.

16. Ma Y, Zhang Z, Liu Y, et al. Nanotubes functionalized with BMP2 knuckle peptide improve the osseointegration of titanium implants in rabbits. J Biomed Nanotechnol. 2015;11(2):236-244.

17. Mozhaev VV. Mechanism-based strategies for protein thermostabilization. Trends Biotechnol. 1993;11(3):88-95.

18. Arakawa T, Prestrelski SJ, Kenney WC, Carpenter JF. Factors affecting short-term and long-term stabilities of proteins. Adv Drug Deliv Rev. 2001;46(1-3):307-326.

19. Wang W. Lyophilization and development of solid protein pharmaceuticals. Int J Pharm. 2000;203(1-2):1-60.

20. Abdelwahed W, Degobert G, Stainmesse S, Fessi H. Freeze-drying of nanoparticles: formulation, process and storage considerations. $A d v$ Drug Deliv Rev. 2006;58(15):1688-1713.

21. Griebenow K, Klibanov AM. Lyophilization-induced reversible changes in the secondary structure of proteins. Proc Natl Acad Sci U S A. 1995;92(24):10969-10976.

22. Kasper JC, Schaffert D, Ogris M, Wagner E, Friess W. Development of a lyophilized plasmid/LPEI polyplex formulation with long-term stability-a step closer from promising technology to application. J Control Release. 2011;151(3):246-255.

23. Lins RD, Pereira CS, Hünenberger PH. Trehalose-protein interaction in aqueous solution. Proteins. 2004;55(1):177-186.

24. Neta T, Takada K, Hirasawa M. Low-cariogenicity of trehalose as a substrate. J Dent. 2000;28(8):571-576.

25. Zhao J, Wang S, Bao J, et al. Trehalose maintains bioactivity and promotes sustained release of BMP-2 from lyophilized CDHA scaffolds for enhanced osteogenesis in vitro and in vivo. PLoS One. 2013;8(1): e54645.

26. Zhang X, Zhang Z, Shen G, Zhao J. Enhanced osteogenic activity and anti-inflammatory properties of Lent-BMP-2-loaded $\mathrm{TiO}_{2}$ nanotube layers fabricated by lyophilization following trehalose addition. Int $J$ Nanomedicine. 2016;11:429-439. 
27. Yu WQ, Jiang XQ, Zhang FQ, Xu L. The effect of anatase TiO2 nanotube layers on MC3T3-E1 preosteoblast adhesion, proliferation, and differentiation. J Biomed Mater Res A. 2010;94(4):1012-1022.

28. Xie G, Sun J, Zhong G, Liu C, Wei J. Hydroxyapatite nanoparticles as a controlled-release carrier of BMP-2: absorption and release kinetics in vitro. J Mater Sci Mater Med. 2010;21(6):1875-1880.

29. Zhao J, Hu J, Wang S, et al. Combination of $\beta$-TCP and BMP-2 genemodified bMSCs to heal critical size mandibular defects in rats. Oral Dis. 2010;16(1):46-54.

30. Li B, Yoshii T, Hafeman AE, Nyman JS, Wenke JC, Guelcher SA. The effects of rhBMP-2 released from biodegradable polyurethane/ microsphere composite scaffolds on new bone formation in rat femora. Biomaterials. 2009;30(35):6768-6779.

31. Rago R, Mitchen J, Wilding G. DNA fluorometric assay in 96-well tissue culture plates using Hoechst 33,258 after cell lysis by freezing in distilled water. Anal Biochem. 1990;191(1):31-34.

32. Livak KJ, Schmittgen TD. Analysis of relative gene expression data using real-time quantitative PCR and the 2(-Delta Delta C (T)) Method. Methods. 2001;25(4):402-408.

33. Zhang W, Wang G, Liu Y, et al. The synergistic effect of hierarchical micro/nano-topography and bioactive ions for enhanced osseointegration. Biomaterials. 2013;34(13):3184-3195.

34. Sciadini MF, Johnson KD. Evaluation of recombinant human bone morphogenetic protein-2 as a bone-graft substitute in a canine segmental defect model. J Orthop Res. 2000;18(2):289-302.

35. Friess W, Uludag H, Foskett S, Biron R, Sargeant C. Characterizaiton of absorbable collagen sponges as recombinant human bone morphogenetic protein-2 carriers. Int J Pharm. 1999;185(1):51-60.

36. Ginebra MP, Traykova T, Planell JA. Calcium phosphate cements as bone drug delivery systems: a review. J Control Release. 2006;113(2): 102-110.

37. Haidar ZS, Hamdy RC, Tabrizian M. Delivery of recombinant bone morphogenetic proteins for bone regenenration and repair. Part B: delivery systems for BMPs in orthopaedic and craniofacial tissue engineering. Biotechnol Lett. 2009;31(12):1825-1835.
38. Huang DG, Liao SJ, Zhou WB, et al. Synthesis of samarium- and nitrogen-co-doped $\mathrm{TiO}_{2}$ by modified hydrothermal method and its photocatalytic performance for the degradation of 4-chlorophenol. J Phys Chem Solids. 2009;70(5):853-859.

39. Jansen JA, Vehof JW, Ruhe PQ, et al. Growth factor-loaded scaffolds for bone engineering. J Control Release. 2005;101(1-3):127-136.

40. Jeon O, Song SJ, Kang SW, Putnam AJ, Kim BS. Enhancement of ectopic bone formation by bone morphogenetic protein-2 released from a heparin-conjugated poly (L-lactic-co-glycolic acid) scaffold. Biomaterials. 2007;28(17):2763-2771.

41. La WG, Jin M, Park S, et al. Delivery of bone morphogenetic protein-2 and substance $\mathrm{P}$ using grapheme oxide for bone regeneration. Int $J$ Nanomedicine. 2014;9(Suppl 1):107-116.

42. La WG, Kang SW, Yang HS, et al. The efficacy of bone morphogenetic protein-2 depends on its mode of delivery. Artif Organs. 2010;34(12): $1150-1153$.

43. Jeon O, Song SJ, Yang HS, et al. Long-term delivery enhances in vivo osteogenic efficacy of bone morphogenetic protein-2 compared to shortterm delivery. Biochem Biophys Res Commun. 2008;369(2):774-780.

44. Uludag H, Gao T, Porter TJ, Friess W, Wozney JM. Delivery systems for BMPs: factors contributing to protein retention at an application site. J Bone Joint Surg Am. 2001;83(A Suppl 1):S128-S135.

45. Boerckel JD, Kolambkar YM, Dupont KM, et al. Effects of protein dose and delivery system on BMP-mediated bone regeneration. Biomaterials. 2011;32(22):5241-5251.

46. Quinlan E, Thompson EM, Matsiko A, O’Brien FJ, Lopez-Noriega A. Long-term controlled delivery of rhBMP-2 from collagen-hydroxyapatite scaffolds for superior bone tissue regeneration. J Control Release. 2015;207:112-119.

47. Le Nihouannen D, Komarova SV, Gbureck U, Barralet JE. Bioactivity of bone resorptive factor loaded on osteoconductive matrices: stability post-dehydration. Eur J Pharm Biopharm. 2008;70(3): 813-818.
International Journal of Nanomedicine

\section{Publish your work in this journal}

The International Journal of Nanomedicine is an international, peerreviewed journal focusing on the application of nanotechnology in diagnostics, therapeutics, and drug delivery systems throughout the biomedical field. This journal is indexed on PubMed Central,

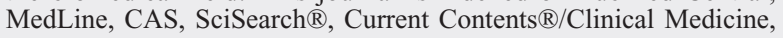

\section{Dovepress}

Journal Citation Reports/Science Edition, EMBase, Scopus and the Elsevier Bibliographic databases. The manuscript management system is completely online and includes a very quick and fair peer-review system, which is all easy to use. Visit http://www.dovepress.com/ testimonials.php to read real quotes from published authors. 